\title{
Development of a novel evaluation method for air particles using surface plasmon resonance spectroscopy analysis
}

\author{
Ryoya Tanaka ${ }^{\mathrm{a}}$, Ryusaku Gomi ${ }^{\mathrm{a}}$, Kunihiro Funasaka ${ }^{\mathrm{b}}$, Daichi Asakawa ${ }^{\mathrm{b}}$, \\ Hiromitsu Nakanishi ${ }^{\mathrm{c}}$ and Hiroshi Moriwaki ${ }^{\mathrm{a} *}$
}

${ }^{a}$ Division of Applied Biology, Faculty of Textile Science and Technology, Shinshu University, 3-15-1

Tokida, Ueda, Nagano 386-8567, Japan

${ }^{b}$ Osaka City Institute of Public Health \& Environmental Sciences, 8-34, Tojo-cho, Tennoji-ku, Osaka 543-0026, Japan

${ }^{c}$ Satellite Venture Business Laboratory, Shinshu University, 3-15-1 Tokida, Ueda, Nagano 386-8567, Japan

* Corresponding author.

E-mail address: moriwaki@shinshu-u.ac.jp (H. Moriwaki).

Tel.: +81(0)268-21-5333

Fax: +81(0)268-21-5331 


\begin{abstract}
The aim of this study is to develop a novel evaluation method for air particles using surface plasmon resonance spectroscopy (SPR) analysis. A L1 sensor chip immobilized liposome was used as a model of the membrane of epithelial cells in organs of respiration. The test suspension dispersed air particles were flowed to the sensor chip. The interaction between the surface of the sensor chip and particulates in the sample solution was detected by SPR. It is deduced that the SPR measurement provides information about the adsorption/desorption behaviors of the particles to the membrane. Environmentally certified reference materials, diesel particulate matter, vehicle exhaust particulates, urban particulate matter, coal fly ash, and rocks, were used as air particulate samples. Filtrates of suspensions of these samples were analyzed by SPR. Each sample revealed characteristic SPR sensor-gram patterns. For example, diesel particulate matters strongly interacted with the lipid bilayer, and were hardly dissociated. On the other hand, coal fly ash and rock particles interacted poorly with the membrane. Establishment of the presented method would link to the novel evaluation or characterization method for air particles.
\end{abstract}

Keywords: atmospheric particles; surface plasmon resonance spectroscopy; model cell membrane; phospholipid bilayer 


\section{Introduction}

The conservation of quality of the atmospheric environment is important for human health. In particular, it is well known that the inhalation of air particles has significant influence on human health. It is considered that these substances are at the root of allergy diseases, such as asthma. ${ }^{1}$

Therefore, they are very significant indicators for the evaluation of the atmospheric environment.

Atmospheric particle matter (PM) consists of a mixture of various substances which enter the atmosphere by anthropogenic and natural pathways. ${ }^{2}$ In particular, it is thought that the inhalation of $\mathrm{PM}_{10}$ (the fraction of aerosol particles with an aerodynamic diameter less than $10 \mu \mathrm{m}$ ) and $\mathrm{PM}_{2.5}$ (an aerodynamic diameter less than $2.5 \mu \mathrm{m}$ ) possibly lead to adverse health effects. ${ }^{3-5}$ Therefore, understanding of their concentrations, characterization, speciation, source, and behavior in body are needed. Especially, since there is little information about the behavior of the particle matters entering the body by inhalation. ${ }^{6}$

Epithelial cells in the throat or nasal passage have been chronically exposed to atmospheric particulates and indoor dust. Therefore, it is important to understand the interaction between the phospholipid bilayer constructed cell membrane of epithelia cells and environmental particulates in order to know the behavior of exposed particles in the body. However, there is no simple method for the analysis of interaction between the mucosal membrane of respiration organs and environmental particles, to the best of our knowledge. 
Surface plasmon resonance spectroscopy (SPR) has been used for measuring adsorption of materials onto surfaces of the sensor chip. Recently, the technique has been applied to the direct analysis of the binding of drugs to phospholiqid vesicles immobilized on a SPR sensor chip. ${ }^{7}$ Miyano et al. reported the evaluation method for the continuity of taste by SPR with sensor chip immobilized liposomes. ${ }^{8,9}$ The sensor chip was the model of the membrane of the lingual cells.

In this study, the interaction of airborne particles with the model cell membrane was investigated by surface plasmon resonance spectroscope with a L1 sensor chip immobilized liposome, 1,2-dioleoyl-sn-glycero-3-phosphocholine (DOPC). The surface of the sensor chip was used as a model of the membrane of the epithelial cells in organs of respiration. The test suspension dispersed indoor dust which was flowed into the cell, and contacted with the sensor chip (Fig. 1).

Environmentally certified reference materials, diesel particulate matter, vehicle exhaust particulates, urban particulate matter, coal fly ash, and rocks, were used as atmospheric particle samples. The diesel exhaust particle is composed of a center core of elemental carbon and adsorbed compounds including heavy metals, poly-aromatic hydrocarbons (PAHs) and nitrated PAHs. It is well known that exposure to vehicle exhaust particulates containing diesel exhaust particles increases the incidence of allergic asthma and airway disorders. ${ }^{10,11}$ Coal fly ash is one of the residues arisen from the combustion. The predominant elements are silicon, iron, aluminum, and calcium. It is well known that various toxic substances, such as arsenic, chromium, lead, vanadium, 
and nickel, were contained as trace constituents. ${ }^{12}$ Rock particles were selected as an airborne particle from a natural source.

These particle samples were dispersed in a buffer and filtered through a $10 \mu \mathrm{m}$ nylon filter or a $0.20 \mu \mathrm{m}$ membrane filter. The obtained filtrates (test suspension A for $10 \mu \mathrm{m}$ nylon filter and test suspension B for $0.20 \mu \mathrm{m}$ membrane filter) were injected into a SPR microscope with a L1 sensor chip immobilized liposome. Test suspension $\mathrm{A}$ is a model of a suspension dispersed $\mathrm{PM}_{10}$. On the other hand, the SPR measurement of test suspension B is aimed at gaining information about the interaction of the liposome with the particulates $(<0.20 \mu \mathrm{m})$ and soluble fraction in the suspension.

\section{Materials and Methods}

DOPC was obtained from Avanty Polar Lipid (Alabaster, AL, USA). HBS-N (running buffer solution for SPR; $0.01 \mathrm{M}$ of 4-(2-hydroxyethyl)-1-piperazineethanesulfonic acid (HEPES), pH 7.4, $0.15 \mathrm{M} \mathrm{NaCl}$ ) was from GE Healthcare (Buckinghamshire, UK). Unless otherwise noted, HBS-N was used as a running buffer. In the case of the SPR measurement at $\mathrm{pH} 4.0$, acetic acid buffer was used as a running buffer. Sodium hydroxide, chloroform, methanol, sodium acetate and acetic acid were purchased from Wako Pure Chemical Industries (Osaka, Japan). 0.1\% Bovine serum albumin (BSA) solution was from Takara Bio Inc. (Shiga, Japan). Distilled water was produced by an automatic water distillation apparatus (WG203; Yamato Scientific, Tokyo, Japan).

\section{Preparation of SPR sensor chip}


The DOPC solution dissolved in chloroform was dried using a vacuum pump, and then hydrated in a HBS-N running buffer at a final concentration of $10 \mathrm{mM}$. The DOPC suspension was frozen $\left(-80^{\circ} \mathrm{C}\right)$, thawed $\left(20^{\circ} \mathrm{C}\right)$, and vortexed to ensure a complete agitation. The DOPC suspension was extruded 25 times through a $50 \mathrm{~nm}$ polycarbonate filter using a Mini-Extruder (Avanti Polar Lipid, Alabaster, AL, USA) to form liposomes. Before addition of the liposome, the L1 sensor chip (GE Healthcare) was attached to the sensor port of a Biacore X system (GE Healthcare) and washed with $40 \mathrm{mM}$ n-octyl- $\beta$-D-glucopyranoside at a flow rate of $10 \mu \mathrm{L} \mathrm{min}{ }^{-1}$ for $10 \mathrm{~min}$. The surface of the $\mathrm{L} 1$ sensor chip can acquire lipid membranes, such as liposome. The liposome was diluted in the HBS-N running buffer to a concentration of $0.5 \mathrm{mM}$. The liposome preparation was added to the sensor chip at a flow rate of $2.0 \mu \mathrm{L} \mathrm{min}^{-1}$ for $15 \mathrm{~min}$ to generate a lipid bilayer on the chip. Erb et al. investigated the surfaces generated by liposome binding to the L1 sensor chip by atomic force microscopy and fluorescence microscopy, and it was confirmed that the liposome fused together, covered the surface homogeneously, and form a stable lipid layer on the sensor chip. ${ }^{13}$ The surface of the sensor chip was washed with $50 \mathrm{mM} \mathrm{NaOH}$ at $2.0 \mu \mathrm{L} \mathrm{min}^{-1}$ for $5 \mathrm{~min}$, and then $100 \mu \mathrm{g} \mathrm{mL} \mathrm{m}^{-1}$ of BSA was added to the sensor chip at $2.0 \mu \mathrm{L} \mathrm{min}^{-1}$ in order to confirm the uniform stabilization of the liposome on the L1 sensor chip. The analysis methods mentioned below were used when the resonance units were < 100.

\section{SPR measurement of particles}


The environmentally certified reference materials used in this study are summarized in Table $\mathbf{1}$. The levels of carbon contents were the certified values of the samples. The configurations of the airborne particulate samples were measured by the scanning electron microscope (JSM-6010LA, JEOL, Tokyo, Japan). The configuration of the coal fly ash particulates was a spherical shape. A $4.0 \mathrm{mg}$ sample of the reference material was added to a HBS-N buffer $(5 \mathrm{~mL})$ and mixed by vortex. The vehicle exhaust particulates were not dispersed with mixing. Therefore, the sample was dispersed by ultrasonic agitation for $1 \mathrm{~min}$. The suspension was filtered through a $10 \mu \mathrm{m}$ nylon filter (N-No508T-K, Tokyo Screen, Tokyo, Japan) or $0.20 \mu \mathrm{m}$ membrane filter (Minisart RC, Sartorius stedim, Goettingen, German). The obtained filtrate was used as a test suspension A for $10 \mu \mathrm{m}$ nylon filter and test suspension B for $0.20 \mu \mathrm{m}$ membrane filter.

The test suspensions A of the atmospheric particles were evaluated by measuring the particle size distribution, and zeta potential. The particle size distribution was analyzed by the dynamic light scattering method, and the zeta potential was measured by the light scattering electrophoresis. The particle size distribution and the zeta voltage of the test suspension A of the atmospheric particles were measured using a Zetasizer Nano Series (Malvern Instruments Limited, Worcestershire, UK).

Test suspensions A and B were measured by SPR. Sample liquids were injected into the Biacore $\mathrm{X}$ system at a flow rate of $2.0 \mu \mathrm{L} \mathrm{min}{ }^{-1}$ for $4 \mathrm{~min}$, and then the running buffer was eluted. The response units (RUs) were measured just before the end of the sample application (4 min) and $1 \mathrm{~min}$ 
after the end of the addition of the samples $(5 \mathrm{~min})$. The SPR data were analyzed using

BIAevaluation software version 4.1.

\section{Results and Discussion}

\section{Characterization of particles}

Environmentally certified reference materials were used for the samples as air particles in this study.

The characteristic features of the samples are summarized in Table 1. The zeta potential of the test suspension of the diesel particle matter and vehicle exhaust particulates showed a peak at -31 and $-24 \mathrm{mV}$ at $\mathrm{pH} 7.4$, which indicates that these particles were dispersed using a negative charge in water. It was reported that diesel exhaust particles and urban organic aerosol contained various carboxylic acids. ${ }^{14}$ The low values of the zeta potential of diesel and the vehicle exhaust particulates would be due to the presence of carboxylic compounds in the particles or the carboxylic group on the surface of the particles. On the other hand, the zeta voltages of the rock and coal fly ash samples (-5.4 and $-11 \mathrm{mV}$, respectively) were higher than those of diesel exhaust particles and vehicle exhaust particulates. The dominant component of the rock and coal fly ash samples is $\mathrm{SiO}_{2}$ (certified $\mathrm{SiO}_{2}$ contents: 63 and 54\%, respectively), and the carbon contents of the rock and coal fly ash samples, $0.29 \mu \mathrm{g} \mathrm{g}^{-1}$ and $1.61 \%$, were lower than those of the diesel exhaust particles and the vehicle exhaust particulates. The functional group to the reveal negative charge would be present at a lower level on the surface of the rock and coal fly ash compared to the diesel exhaust particles and vehicle 
exhaust particulates.

The average particle size of the airborne particulates in test suspension A ranged from 1300 to $2300 \mathrm{~nm}$, and it was confirmed that the sizes of the particles in test suspensions A were below $10 \mu \mathrm{m}$.

Therefore, test suspension A could be used as a model for a suspension dispersed $\mathrm{PM}_{10}$.

\section{SPR sensor-gram patterns}

The SPR sensor-gram pattern obtained by SPR measurement reflects the interaction between the substances in a sample solution and the surface of the SPR sensor chip. Furthermore, the shape of the SPR sensor-gram is related to the strength of the interaction of the substances in a sample solution with the sensor chip. In the case of the high interaction of the substances in a sample solution with liposome, the RU value gradually increases by the application of the sample. After application of the sample, the RU value slowly decreases due to the slow dissociation of the binding components from the sensor chip. On the other hand, a rectangle-shaped sensor-gram is observed when the interaction between the substances in a sample solution and liposome is weak. The RUs returned to the baseline level immediately after the end of the application of the sample because of the quick release of the interacted components.

In reference 8 , the residual ratio was suggested to be the indicator of the strength of the interaction between the substances in a sample solution and the liposome immobilized on the L1 sensor chip. The residual ratio $(b /(a+b))$ was calculated as follows. The RU value, $(a+b)$, measured 
just before the end of the sample application was divided by the RU value (b) measured 3 min after the end of the sample application. It is thought that the values of the residual ratio are correlated to the strengths of the interaction between the substances and the sensor chip.

The SPR sensor-gram of air particles in this study showed noise peaks at 2 min after the end of the sample application (measurement time: 6 min). This phenomena would occur by desorption of the substances adsorbed on the tubes in the SPR spectroscope. Therefore, the RU values at just before the end of the sample application (measurement time: $4 \mathrm{~min}$ ) and $1 \mathrm{~min}$ after the end of sample application (measurement time: $5 \mathrm{~min}$ ) were measured in order to avoid the influences by the noise peaks (Fig.2). The residual ratio was calculated by the division (the RU value at measurement time at $5 \mathrm{~min} /$ the RU value at measurement time at $4 \mathrm{~min}$ ), and the value was regarded as a parameter to indicate the interaction between the substances in the airborne particulate and liposome. For example, the standard deviation of the residual ratio $(b /(a+b))$ for the test suspension $A$ of the vehicle exhaust particulates was less than $10 \%(7.7 \%)$ of the average $(n=3)$.

\section{Interactions of particulate with the liposome}

Sensor-grams of the test suspension A of the airborne particulate samples and the test suspension B are shown in Figs 3 and 4, respectively. The residual ratios calculated by the SPR sensor-gram patterns of the airborne particulate samples are listed in Table 2. In general, the intensity of the peak in the SPR sensor-gram relates to the total mass of the substances interacted with the SPR sensor 
chip. Therefore, the peak intensity provides significant insight into the interaction of a substance with the sensor chip. However, it is difficult to discuss the interaction of substances in suspensions by the peak intensities of the SPR sensor-gram, because there is no information about the concentrations and densities of particulates in test suspensions.

On the other hand, the pattern of the SPR sensor-gram represents the strength of the interaction of substances in the test suspensions with the SPR sensor chip. Therefore, it is expected that the binding activities and desorption behavior with liposome can assess by the comparison of SPR sensor-gram patterns of the airborne particulate samples.

It was discovered by the sensor-gram of the diesel particulate matters that the substances contained in test suspension A of the diesel particulate matters strongly interacted with the lipid bilayer, and were hardly dissociated. The residual ratio of the diesel particulate matters was highest of the 5 airborne particulate samples. The SPR sensor-grams of the test suspension A for vehicle exhaust particulate and urban particulate matter were a similar pattern. Furthermore, the sensor-gram pattern of coal fly ash was similar to that of the rock sample, and the residual ratios of these samples were lower levels compared to those of the other samples.

The peak intensities for test suspension $\mathrm{B},(\mathrm{a}+\mathrm{b})_{\mathrm{B}}$, were lower than those of test suspension $\mathrm{A}$, $(a+b)_{A}$, for all samples. However, the peak intensities of test suspension B for urban particulate matter, rock, and coal fly ash were 74,63 , and $50 \%$ of the peak intensities of test suspension A for 
each sample. These results suggest that the contribution of the mixture of the particulates $(<0.20 \mu \mathrm{m})$ and the soluble fraction of suspensions to the SPR peak intensities of test suspension A for these samples is more than $50 \%$.

The residual ratios of test suspension B for the vehicle particulate, rock, and coal fly ash were low level $(<0.1)$. On the other hand, the residual ratios of the diesel particulate matter and the urban particulate matter were higher $(0.24$ and 0.15 , respectively). These results indicate that the particulates $(<0.20 \mu \mathrm{m})$ and the soluble fraction in the test suspension B of the diesel particulate matter and urban particulate matter interacted with liposome.

Next, in order to understand the influence of the flow rate of the sample liquids on the residual ratios, SPR measurements were also performed at flow rates of $8.0 \mu \mathrm{L} \mathrm{min}{ }^{-1}$. As results, the residual ratios were not significantly changed when the flow rate was increased from 2.0 to $8.0 \mu \mathrm{L} \mathrm{min}^{-1}$. For example, the residual ratios for the rock sample (test suspension A) were 0.16 and 0.17 for the flow rate at 2.0 and $8.0 \mu \mathrm{L} \mathrm{min}{ }^{-1}$, respectively. These results suggest that the interactions between the particulates in the sample liquids and the liposome were strong enough to avoid accelerating desorption of the particulates by the increase of the flow rate from 2.0 to $8.0 \mu \mathrm{L} \mathrm{min}^{-1}$.

It is thought that the difference in the interaction of liposome with the airborne particulate samples is owed to several factors. There were no significant relationships between the residual ratios and the average particle sizes in test suspension A. On the other hand, there was a tendency 
that the higher residual ratios were observed, when the zeta potentials of the test suspension A were lower (Fig.5). However, the residual ratio of rock was higher than that of coal fly ash, though the zeta potential of rock was higher than that of coal fly ash. This result suggests that the residual ratio was influenced by not only parameters related to the zeta potential but also other factors, such as configuration of the samples. The zeta potential of the liposome in the suspension $(0.20 \mathrm{mM}$; HBS-N solution) showed a peak at $-13.7 \mathrm{mV}$ at $\mathrm{pH} 7.4$, which indicates that the interaction between particles and the liposome does not mainly depend on the Coulomb attraction by the surface charge. In addition, the vehicle exhaust particulates and the diesel particulate matter, which contained carbon at high rates $(>50 \%)$, showed high residual ratios ( 0.57 and 0.96 , respectively).

It is well known that the interaction of liposome with substances relates to hydrogen bonding. For example, it was reported that the interaction of liposome with epigallocatechin gallate (EGCG) was higher than that with catechin. ${ }^{8}$ It was suggested that the result was caused by a gallate moiety of EGCG that forms hydrogen bonds with the hydrophilic sites of liposome. ${ }^{15}$ When more polar functional groups, such as a carboxyl group, exist at the surface of the particulates, lower zeta potentials of the suspension would be observed, and particulates containing many polar functional groups can form hydrogen bonding, interact with liposome, and access to the surface of the liposome. Then, the hydrophobic interaction between lipid moiety of liposome and the lipophilic sites in the particulates and the physical sorption of the particulates to the liposome would arise the strong 
interactions of the liposome with the particulates in test suspension A. That is to say, it is considered that the particulates containing both many polar functional groups and lipophilic sites reveal high residual ratios. In addition, the structure of diesel particulate matter generally consists of the beaded soot, and it is thought that the particulate is easy to form physical sorption with the liposome. ${ }^{16}$ The result that test suspension B of the diesel particulate matter showed a high residual ratio would be caused by hydrogen bonding between liposome on the SPR sensor chip and dissolved long-chain alkyl acids, which were contained in the diesel particulate matter. ${ }^{17}$

Next, in order to gain the information about the interaction between the particle and the liposome, SPR measurements of the test suspensions A of vehicle exhaust gas sample and diesel particulate matter at $\mathrm{pH} 4.0$ were performed. The residual ratio was 0.97 and 0.996 for vehicle exhaust gas sample and diesel particulate matter, respectively. The values of the residual ratios were increased with decrease of $\mathrm{pH}$ from 7.4 to 4.0. The increase of the residual ratio under lower $\mathrm{pH}$ condition would be due to the enhancement of the non-ionic interactions, such as hydrogen bonding and hydrophobic interaction. It was reported that the interaction between liposome and a protein was significantly increased when $\mathrm{pH}$ was decreased from 7 to 4 , because of the increase of non-ionic interactions. ${ }^{18}$ Further information about the interaction between the particles and the liposome would be obtained by SPR measurement under various conditions, such as $\mathrm{pH}$ and the concentrations of the particles. 
The interaction of liposome (dimyristoylphosphatidylcholine vesicles) with polycyclic aromatic hydrocarbons (PAHs) observed by the calorimetric approach was reported. ${ }^{19}$ In reference, it was reported that powdered PAH solids and PAHs adsorbed on silica gel were unable to migrate through an aqueous medium to reach the biological membrane, and the PAHs dispersed in the lipophilic medium were able to interact with liposome. In this study, the SPR measurements were performed in an aqueous buffer solution. Therefore, it is considered that the possibility of low polarity compounds, such as PAHs contained in the airborne particulate samples, interacting with liposome is low. However, there is a possibility that the hydrogen bonding between the polar functional groups on the air particles and the liposome assists the access of PAHs adsorbed on the particles to the liposome.

\section{Conclusion}

It was discovered that the adsorption behaviors of airborne particles onto the liposome immobilized on the L1 sensor chip were different by the generation source of the airborne particulate samples. In addition, it was indicated that the sorptive property of the particulates onto the liposome was related to the carbon content and the zeta potential of the sample. The procedure described in this study is very simple, and a straightforward model is proposed to describe the interaction of the airborne particulates with the membrane of the epithelial cells in organs of respiration. The presented method would be useful for the study of air pollution as a novel assessment technique for air particles. Characteristic SPR sensor-gram patterns for each atmospheric particulate sample were 
observed. This result suggests that the presented method would also provide information about the source of a sample of atmospheric particles obtained at a site. Therefore, the method is useful to study the source characterization of air pollution. Furthermore, the method would be also useful for researching the risk assessment of other pollutants, such as nano-materials. However, the relationship between the behavior of airborne particulates in a body and the impact on health has not been clarified at this stage. The next step of this research is to develop the assessment method for the relationship between the results obtained by the presented analysis and the influence of the airborne sample on human health.

\section{Acknowledgement}

This work was supported by the Shinshu University Satellite Venture Business Laboratory (SVBL).

The authors belonging to the Shinshu University were the members of the "Project Device Experts (P-DEX)" organized by SVBL. We wish to thank Mr. Masashi Nakaochi and Yusaku Ogai (SVBL) for their support on the SPR measurements.

\section{References}

1 R. J. Delfino, P. J. E. Quintana, J. Floro, V. M. Gastañaga, B. S. Samimi, M. T. Kleinman, L. J. S. Liu, C. Bufalino, C. F. Wu, C. E. McLaren, Environ. Health Perspect., 2004, 112(8), 932-941.

2 Y. Gao, E. D. Nelson, M. P. Field, Q. Ding, H. Li, R. M. Sherrell, C. L. Gigliotti, D. A. Van Ry, T. R. Glenn, S. J. Eisenreich, Atmospheric Environ., 2002, 36, 1077-1086. 
3 C. I. Davidson, R. F. Phalen, P. A. Solomon, Aero. Sci. Technol., 2005, 39, 737-749.

4 M. Roy, U. Harrison, Y. Jianxin, Sci. Total Environ., 2000, 249, 85-101.

5 G. M. Marcazzan, S. Vaccaro, G. Valli, R. Vecchi, Atmospheric Environ., 2001, 35, 4639-4650.

6 T. B. Martonen, J. D. Schroeter, Toxicol. Lett., 2003, 138, 119-132.

7 M. R. Nussio, M. J. Sykes, J. O. Miners, J. G. Shapter, Chem. Med. Chem., 2007, 2, 366-373.

8 M. Miyano, H. Yamashita, T. Sakurai, K. Nakajima, K. Ito, T. Misaka, Y. Ishimaru, K. Abe, T. Asakura, J. Agric. Food Chem., 2010, 58, 11870-11875.

9 T. Asakura, M. Miyano, H. Yamashita, T. Sakurai, K. Nakajima, K. Ito, T. Misaka, Y. Ishimaru, K. Abe, Flavoru Fragr. J., 2011, 26, 274-278.

10 H. Takano, T. Yoshikawa, T. Ichinose, Y. Miyabara, K. Imaoka, and M. Sagai, Am. J. Respir. Crit. Care Med., 1997, 156, 36-42.

11 A. G. Miguel, G. R. Cass, M. M. G. lovsky, J. Weiss, Environ. Sci. Technol., 1999, 33, 41594168.

12 P. J. A. Borm, Ann. Occup. Hyg., 1997, 41, 659-676.

13 E.-M. Erb, X. Chen, S. Allen, C. J. Roberts, S. J. B. Tendler, M. C. Davies, S. Forsen, Anal Biochem., 2000, 280, 29-35.

14 W. F. Rogge, M. A. Mazurek, L. M. Hildemann, G. R. Cass, Atmosperic Environ., 1993, 27A, 1309-1330. 
15 Y. Sun, W. C. Hung, F. Y. Chen, C. C. Lee, H. W. Huang, Biophys. J., 2009, 96, 1026-1035.

16 J. J. Vostal, Bull. NY. Acad. Med., 1980, 56, 914-934.

17 W. F. Rogge, L. M. Hildemann, M. A. Mazurek, G. R. Cass, Environ. Sci. Technol., 1997, 27, 636-651.

18 M. Rytömaa, P. Mustonen, P. K. J. Kinnunen, J. Biol. Chem., 1992, 267, 22243-22248.

19 F. Castelli, V. Librando, M. G. Sarpietro, Environ. Sci. Technol., 2002, 36, 2717-2723. 
Table 1 . The reference standard materials used in this study

\begin{tabular}{|c|c|c|c|c|c|}
\hline \multirow[b]{2}{*}{ Sample } & \multirow[b]{2}{*}{$\begin{array}{l}\text { Reference } \\
\text { standard } \\
\text { material }\end{array}$} & \multirow[b]{2}{*}{$\begin{array}{l}\text { Carbon } \\
\text { content }^{\mathrm{a}}\end{array}$} & \multirow[b]{2}{*}{ Comments } & \multicolumn{2}{|c|}{ Test suspention A } \\
\hline & & & & $\begin{array}{l}\text { Zeta } \\
\text { potential } \\
(\mathrm{mV})\end{array}$ & $\begin{array}{l}\text { average } \\
\text { particle size } \\
\quad(\mathrm{nm})\end{array}$ \\
\hline $\begin{array}{l}\text { Vehicle } \\
\text { exhaust } \\
\text { particulates }\end{array}$ & NIES No.8 & $80 \%$ & $\begin{array}{l}\text { The sample was collected in } \\
\text { the tunnel of a highway. }\end{array}$ & -24 & 1900 \\
\hline $\begin{array}{l}\text { Diesel } \\
\text { particulate } \\
\text { matter }\end{array}$ & SRM 2975 & $60 \%$ & $\begin{array}{l}\text { The sample was collected from } \\
\text { a diesel-powered industrial } \\
\text { forklift. }\end{array}$ & -31 & 1600 \\
\hline $\begin{array}{l}\text { Urban } \\
\text { particulate } \\
\text { matter }\end{array}$ & SRM 1648a & $12.7 \%$ & $\begin{array}{l}\text { The material was collected in } \\
\text { St. Louis. }\end{array}$ & -18 & 2300 \\
\hline Coal fly ash & $\begin{array}{l}\text { Environmental } \\
\text { agency, Japan } \\
\text { (1980) }\end{array}$ & $1.61 \%$ & $\begin{array}{l}\text { The particle matter in a coal } \\
\text { furnace was sampled by an } \\
\text { electric dust collector. }\end{array}$ & -11 & 1300 \\
\hline Rock & NCS DC71302 & $\begin{array}{c}0.29 \mu \mathrm{g} \\
\mathrm{g}^{-1}\end{array}$ & $\begin{array}{l}\text { The sample is the andesite } \\
\text { standard rock material. }\end{array}$ & -5.4 & 1300 \\
\hline
\end{tabular}

${ }^{a}$ The levels of carbon content were the certified values of the reference standard materials.

Table 2. The residual ratios calculated by the SPR sensor-gram patterns of the airborne particulates samples

\begin{tabular}{|c|c|c|c|c|c|c|c|c|}
\hline \multirow[t]{2}{*}{ Sample } & \multirow{2}{*}{$\begin{array}{c}\text { Reference standard } \\
\text { material }\end{array}$} & \multicolumn{3}{|c|}{ Test suspention A } & \multicolumn{3}{|c|}{ Test suspention B } & \multirow{2}{*}{$\begin{array}{l}(\mathrm{a}+\mathrm{b})_{\mathrm{B}} \\
/(\mathrm{a}+\mathrm{b})_{\mathrm{A}}\end{array}$} \\
\hline & & $a+b$ & $\mathrm{~b}$ & $\mathrm{~b} /(\mathrm{a}+\mathrm{b})$ & $a+b$ & $\mathrm{~b}$ & $\mathrm{~b} /(\mathrm{a}+\mathrm{b})$ & \\
\hline $\begin{array}{l}\text { Vehicle exhaust } \\
\text { particulates }\end{array}$ & NIES No.8 & 110 & 62 & 0.57 & 39 & 3.9 & 0.099 & 0.35 \\
\hline $\begin{array}{l}\text { Diesel particulate } \\
\text { matter }\end{array}$ & SRM 2975 & 340 & 330 & 0.96 & 57 & 14 & 0.24 & 0.17 \\
\hline $\begin{array}{l}\text { Urban particulate } \\
\text { matter }\end{array}$ & SRM 1648a & 190 & 84 & 0.44 & 140 & 22 & 0.15 & 0.74 \\
\hline Coal fly ash & $\begin{array}{l}\text { Environmental agency, } \\
\text { Japan (1980) }\end{array}$ & 54 & 5.0 & 0.092 & 27 & 1.3 & 0.049 & 0.50 \\
\hline Rock & NCS DC71302 & 40 & 6.3 & 0.16 & 25 & 0.0 & 0.0 & 0.63 \\
\hline
\end{tabular}

a The ratios of peak intensity $(a+b)$ of Test suspension A and Test suspension B are listed. 


\section{$\underline{\text { Figure captions }}$}

Fig. 1 The simplified schematic of the SPR optical detection system in this study.

Fig. 2 The method of calculation for the residual ratio on the lipid bilayer.

Fig. 3 Sensor-grams of test suspension (A) of the airborne particulate samples.

Fig. 4 Sensor-grams of test suspension (B) of the airborne particulate samples.

Fig. 5 The relationship between the zeta potential of test suspension A and the residual ratio obtained by the SPR measurement of test suspension A. 


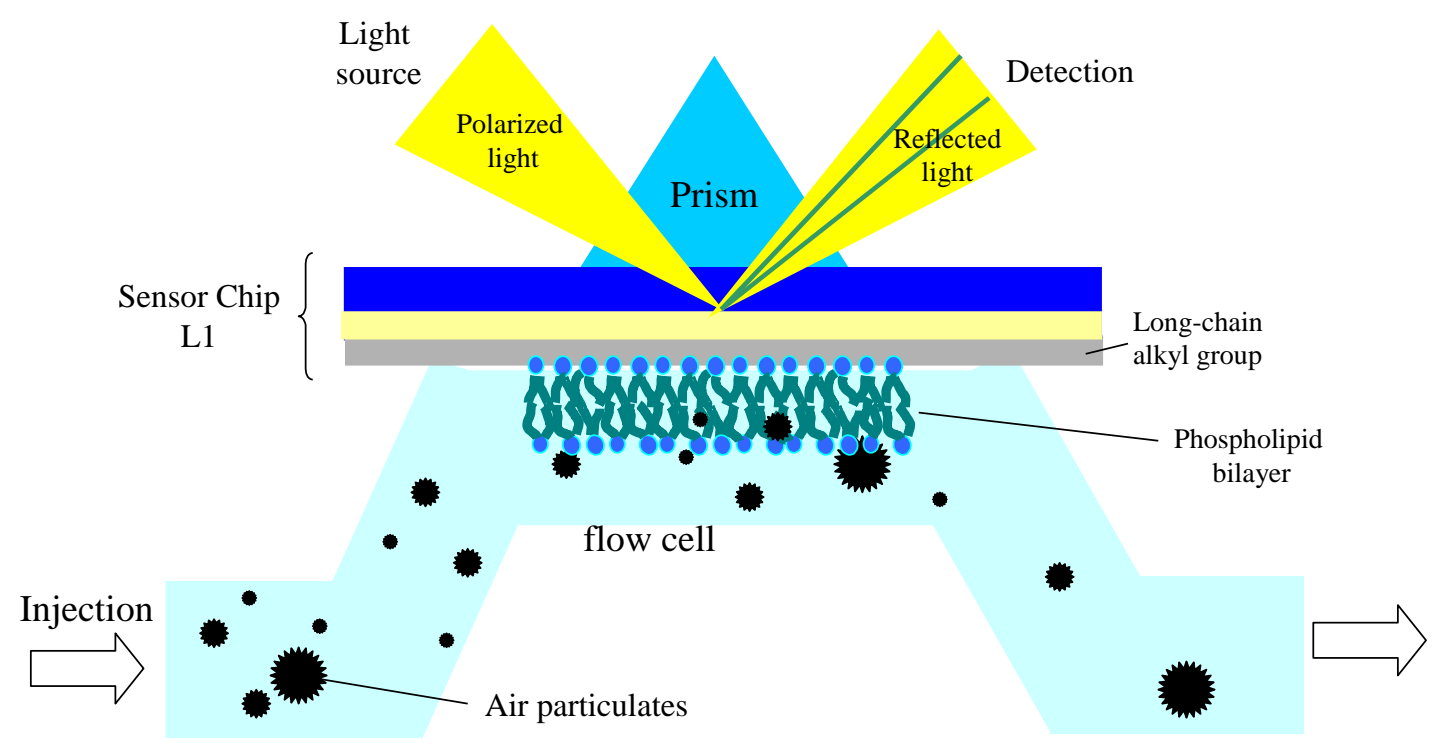

Fig. 1 


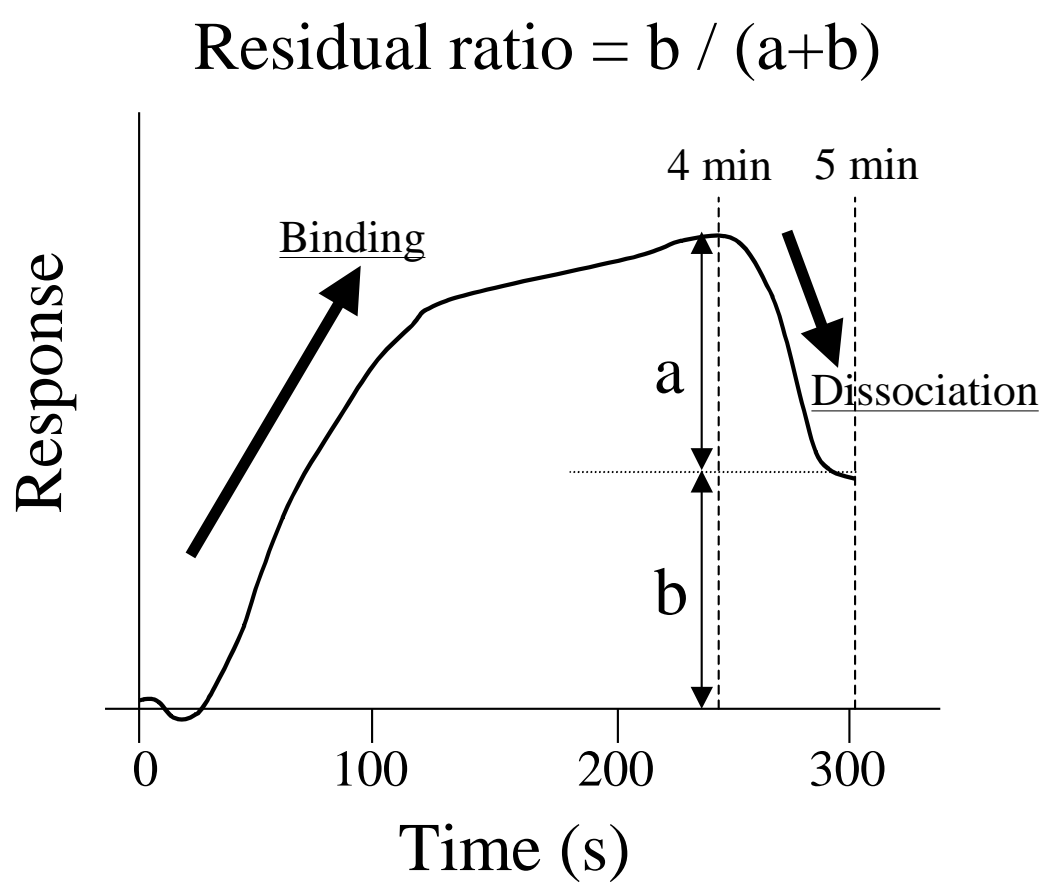

Fig. 2 

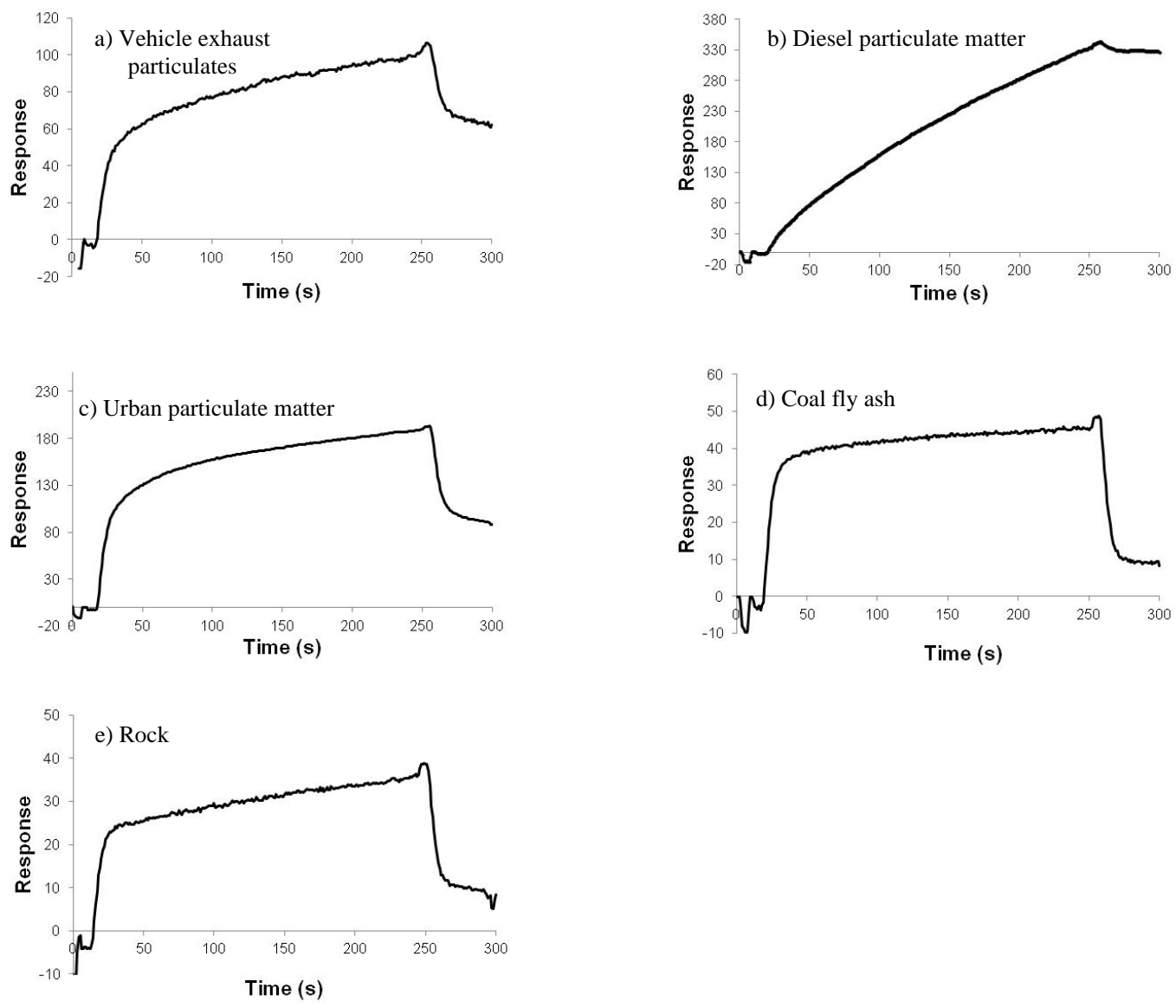

Fig. 3 

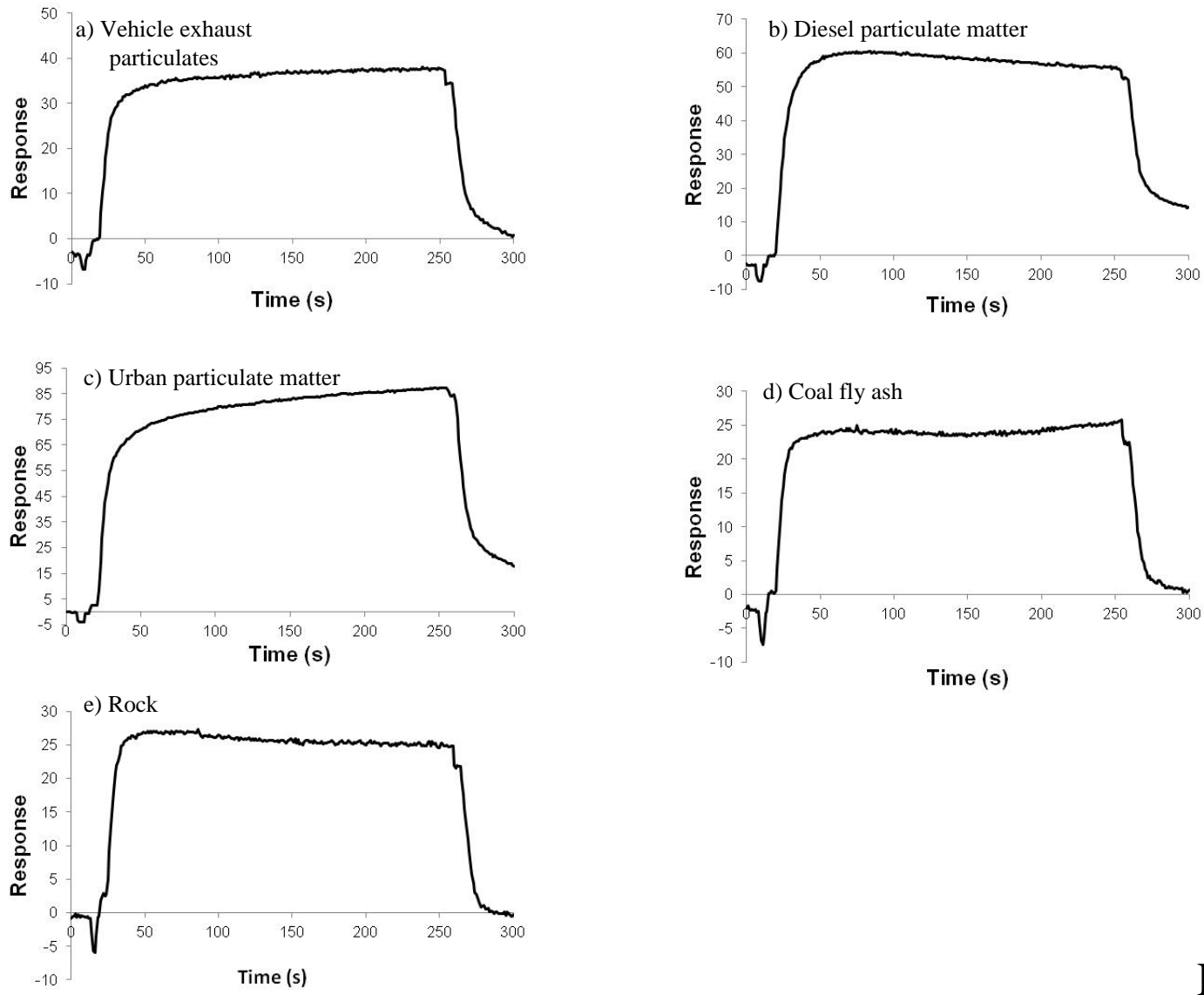

Fig. 4 


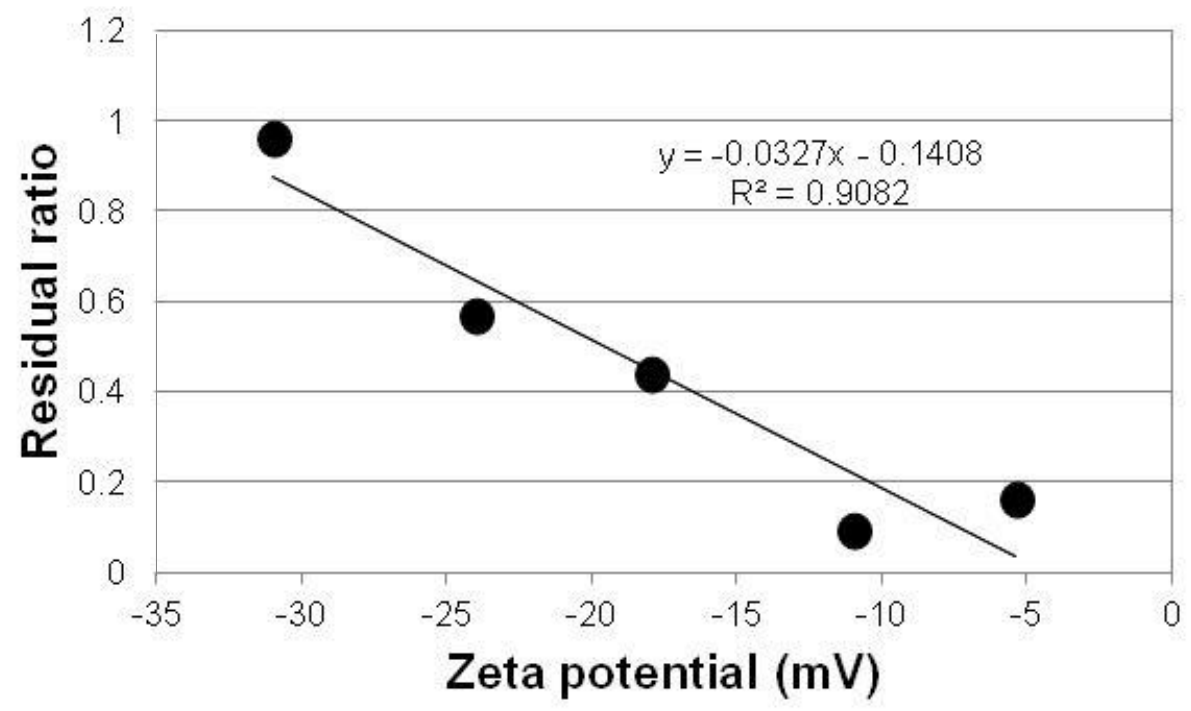

Fig. 5 